\title{
The role of osteopontin in inflammatory processes
}

\author{
Susan Amanda Lund • Cecilia M. Giachelli • \\ Marta Scatena
}

Received: 15 May 2009/Accepted: 9 September 2009/Published online: 2 October 2009

(C) The Author(s) 2009. This article is published with open access at Springerlink.com

\begin{abstract}
Osteopontin (OPN) is a matricellular protein that mediates diverse biological functions. OPN is involved in normal physiological processes and is implicated in the pathogenesis of a variety of disease states, including atherosclerosis, glomerulonephritis, cancer, and several chronic inflammatory diseases. Through interactions with several integrins, OPN mediates cell migration, adhesion, and survival in many cell types. OPN also functions as a Th1 cytokine, promotes cell-mediated immune responses, and plays a role in chronic inflammatory and autoimmune diseases. Besides its function in inflammation, OPN is also a regulator of biomineralization and a potent inhibitor of vascular calcification.
\end{abstract}

Keywords Inflammation - Matricellular protein ·

Osteopontin

$\begin{array}{ll}\text { Abbreviations } \\ \text { DC } & \text { Dendritic cell } \\ \text { IFN } & \text { Interferon } \\ \text { MMP } & \text { Matrix metalloproteinase } \\ \text { OPN } & \text { Osteopontin } \\ \text { PBMCs } & \text { Peripheral blood mononuclear cells }\end{array}$

\section{Introduction}

OPN is a secreted phosphorylated glycoprotein that mediates diverse biological functions. Originally isolated

S. A. Lund $\cdot$ C. M. Giachelli $\cdot$ M. Scatena $(\bowtie)$

Department of Bioengineering, University of Washington,

Box 358056, Seattle, WA 98195, USA

e-mail: mscatena@u.washington.edu from bone, OPN was later shown to have a wider distribution (Brown et al. 1992). In adults, OPN expression is normally limited to the bone, kidney, and epithelial linings, and is secreted in bodily fluids including milk, blood and urine (Chen et al. 1993). In contrast to its restricted distribution in normal tissue, OPN is strikingly upregulated at sites of inflammation and tissue remodeling (Liaw et al. 1998; O'Brien et al. 1994). OPN exists both as a component of the extracellular matrix and as a soluble cytokine. Physiologically OPN is thought to regulate biomineralization in bone tissue, and to reduce growth and aggregation of calcium crystals in epithelial tissues (Wesson et al. 2003). OPN has also been implicated in a variety of disease states, where it mediates diverse cellular functions such as adhesion, migration, and survival of several different cell types, including regulating and propagating inflammatory responses of macrophages, Tcells, and dendritic cells. The pleiotropic nature of OPN may reflect the various isoforms, post-translational modifications, and diversity of cell types which OPN can interact with. Clinically, OPN plasma levels are correlated with chronic inflammatory diseases such as Crohn's disease (Agnholt et al. 2007), cancer (El-Tanani et al. 2006), atherosclerosis, aortic abdominal aneurysms (Golledge et al. 2007), and autoimmune diseases including lupus (Kariuki et al. 2009), multiple sclerosis (Comabella et al. 2005), and rheumatoid arthritis (Sennels et al. 2008). In this review we will focus on the role of OPN in inflammation biology.

\section{OPN structure}

OPN was originally isolated from bone and was later independently identified as secreted phosphoprotein I 
(SppI) and early T-lymphocyte activation 1 (Eta-1) (Senger et al. 1989; Patarca et al. 1989). OPN is a member of the SIBLING (Small Integrin-Binding Ligand, N-linked Glycoprotein) family of proteins, which map to human chromosome 4 (Fisher et al. 2001). OPN is synthesized as an approximately $32 \mathrm{kDa}$ protein, but due to extensive posttranslational modifications its apparent molecular mass ranges from 45 to $75 \mathrm{kDa}$ (Kazanecki et al. 2007). OPN possesses a negative charge due to a preponderance of acidic amino acids and serine phosphorylation. OPN also contains calcium binding sites and two putative heparin binding domains (Kon et al. 2008). OPN can interact directly with extracellular matrix proteins including fibronectin (Mukherjee et al. 1995) and collagen type I (Chen et al. 1992; Martin et al. 2004).

\section{Adhesion motifs}

OPN has multiple functional adhesive motifs, which allows interactions with many cell types including smooth muscle cells, endothelial cells, and inflammatory cells, thus mediating a broad range of biological functions. The OPN protein is poorly conserved among species $(63 \%$ human to mouse, $30 \%$ human to chicken) however its functional domains are conserved. The highly conserved motifs include: abundance of acidic residues, the RGD integrin binding domain, similar phosphorylation and glycosylation motifs, and at least one site of controlled proteolysis (Bellahcene et al. 2008). The adhesive RGD domain of OPN mediates interactions via $\alpha_{\mathrm{v}} \beta_{1}, \alpha_{\mathrm{v}} \beta_{3}, \alpha_{\mathrm{v}} \beta_{5}, \alpha_{\mathrm{v}} \beta_{6}$, $\alpha_{8} \beta_{1}$, and $\alpha_{5} \beta_{1}$ integrins (Liaw et al. 1995; Yokosaki et al. 2005; Denda et al. 1998; Hu et al. 1995). Immediately Cterminal to the RDG motif is a cryptic SVVYGLR (SLAYGLR in mice) sequence that becomes exposed upon cleavage with thrombin and mediates interactions with $\alpha_{9} \beta_{1}, \alpha_{4} \beta_{1}$, and $\alpha_{4} \beta_{7}$ integrins (Yokosaki et al. 1999; Ito et al. 2009; Green et al. 2001). Finally, the ELVTDFTDLPAT (human OPN) domain of OPN has also been described to bind to $\alpha_{4} \beta_{1}$ (Bayless and Davis 2001).

In addition to interacting with integrins, OPN has also been reported to interact with $\mathrm{CD} 44$, the hyaluronic acid receptor (Weber et al. 1996). A number of different CD44 isoforms exist due to alternative splicing of the 10 variant exons and while OPN can bind some CD44 splice variants, notably v6 and v7, OPN does not bind to the standard isoform, CD44H (Smith et al. 1999; Katagiri et al. 1999). Further, interactions between OPN and CD44 appears to be mediated via $\beta_{1}$ integrins in an RGD independent manner (Katagiri et al. 1999). Other studies indicate interactions between the C-terminal fragment of thrombin cleaved OPN and a CD44 variant (Weber et al. 2002). However, the precise domain of OPN that interacts with CD44 has not been identified. In addition, growing evidence suggests that
OPN is a major regulator of CD44 surface expression, especially in osteoclasts (Chellaiah et al. 2003; Marroquin et al. 2004).

\section{Post-translational modifications}

OPN is subject to extensive post-translational modifications including serine and threonine phosphorylation. Phosphorylation is cell specific with phosphorylation levels varying depending on the tissue type. OPN in milk is highly phosphorylated with human milk OPN containing 36 phosphate sites (Christensen et al. 2005). Phosphorylation tends to occur in clusters separated by stretches of unmodified residues. Normal rat kidney cells can secrete both phosphorylated and non-phosphorylated forms, indicating regulated control of phosphorylation (Singh et al. 1990). In some cases, OPN function is tightly controlled by phosphorylation state. Calcification of smooth muscle cells in vitro is inhibited by native OPN, but desphosphorylated or recombinant bacterially produced OPN has no effect on calcification (Jono et al. 2000). Similarly, in vivo in OPN-null mice, phosphorylated OPN, but not non-phosphorylated, prevents ectopic calcification in a subcutaneous model of bioprosthetic valve mineralization (Ohri et al. 2005). In contrast, the adhesive activity of OPN is not dependent on posttranslational modifications, since bacterially derived recombinant OPN has been shown to support cell adhesion in a wide variety of cell types (Gao et al. 2004; Xuan et al. 1994). OPN is also subject to sulfation (Nagata et al. 1989), glycosylation (Sorensen et al. 1995) and transglutamination (Beninati et al. 1994). Interestingly, polymerization of OPN by transglutaminase 2 has been reported to increase the adhesive activity of OPN via the $\alpha_{9} \beta_{1}$ integrin, independent of the SVVYGLR adhesion domain (Nishimichi et al. 2009). Precise regulation of OPN post-translational modifications may represent a mechanism to control OPN function.

\section{Proteolytic processing}

The bioactivity of OPN can be further regulated by proteolytic processing. OPN is a substrate for thrombin and the matrix metalloproteinases, MMP-3 (stromelysin-1), MMP-7 (matrilysin), MMP-2 and MMP-9 (Agnihotri et al. 2001; Dean and Overall 2007; Takafuji et al. 2007). Human OPN contains three cleavage sites for MMPs; Gly ${ }_{166^{-}}$ $\mathrm{Leu}_{167}, \mathrm{Ala}_{201}-\mathrm{Tyr}_{202}$, and $\mathrm{Asp}_{210}-\mathrm{Leu}_{211}$. The thrombin cleavage site generating a RGD and SVVYGLR (SLAYGLR in mice) is conserved in human and mice. Thrombin cleavage of OPN, $\operatorname{Arg}_{168}$-Ser $_{169}$ in humans and $\operatorname{Arg}_{153}$-Ser $_{154}$ in mice, reveals a cryptic SVVYGLR binding domain capable of fostering interactions with $\alpha_{9} \beta_{1}$ (Smith 
and Giachelli 1998; Smith et al. 1996) and $\alpha_{4} \beta_{1}$ (Bayless and Davis 2001) integrins. Thus, the known adhesive functional domains of OPN are located in the thrombin cleaved N-terminal fragment. Little is known about the role of C-terminal fragments; however, as described above, it has been suggested to contain a CD44 binding domain (Weber et al. 2002; Takafuji et al. 2007).

Proteolytic processing may represent a way to locally regulate the function of OPN as the functional properties of cleaved OPN differ from those of the intact molecule. Of particular interest, rather than mediating degradation and inactivating OPN-mediated functions, proteolytic processing of OPN can increase the biological activity of the molecule (O'Regan et al. 1999). OPN and MMPs are colocalized during wound healing and tumorigenesis, indicating there may be an in vivo role for proteolyzed forms of OPN (Senger et al. 1994). Few studies suggest that OPN fragments may play a functional role in vivo. Enhanced production of the thrombin cleaved form of OPN is found in the synovial fluid of patients with rheumatoid arthritis (Ohshima et al. 2002) and the cryptic SLAYGLR motif was found to play an essential role in a murine and a primate model of rheumatoid arthritis (Yamamoto et al. 2003, 2007). An antibody against the SLAYGLR sequence inhibited inflammatory cell influx into arthritic joints and attenuated the severity of disease. The human OPN derived peptide SVVYGLR has also been found to induce angiogenesis in vitro and in vivo (Hamada et al. 2003, 2007). Several in vitro studies have demonstrated that the $\mathrm{N}$-terminal fragments generated both by thrombin cleavage and MMP cleavage induced enhanced adhesion when compared to the full length molecule. This appears to be due mostly to increased activity of the RGD site, perhaps an indication of conformational change resulting in higher affinity binding (Senger and Perruzzi 1996; Smith and Giachelli 1998; Agnihotri et al. 2001). The SVVYGLR cryptic domain exposed following thrombin cleavage is also able to induce adhesion and migration through the $\alpha_{4}$ and $\alpha_{9}$ integrins (Smith and Giachelli 1998). However, the $\alpha_{9}$-dependent adhesion and migratory functions are completely lost in the N-terminal MMP generated fragment, as $\operatorname{Arg}_{168}$ seems to be required for $\alpha_{9}$-dependent binding (Yokosaki et al. 2005; Ito et al. 2009). In contrast, $\alpha_{4}$ dependent adhesion and migratory functions are only partially lost in the N-terminal MMP generated fragment (Ito et al. 2009). The C-terminal fragment of OPN generated by thrombin and MMP cleavage does not contain any integrin adhesive domains, it does not mediate adhesion when presented in immobilized form to cells and, in contrast, it appears to suppress OPN mediated adhesion and migration in monocyte-derived cells (Gao et al. 2004; Smith et al. 1996; Maeda et al. 2001; Takahashi et al. 1998)
Intracellular OPN

An intracellular form of OPN (iOPN) has been reported to be expressed in dendritic cells and macrophages (Shinohara et al. 2006, 2008a, b; Zohar et al. 2000). Studies by Shinohara et al. suggest that the intracellular form of OPN is generated due to translation initiation downstream of the usual start site in bone marrow-derived DCs and transfected 293 T cells. Utilization of this downstream start site generates the truncated iOPN form that lacks the $\mathrm{N}$ terminal signal sequence and consequently localizes to the cytoplasm, where it may associate with TLR9 and the MyD88 adaptor molecule (Shinohara et al. 2008a). The interaction of iOPN with MyD88 appears to activate the transcription factor IRF7 and to induce expression of IFN- $\alpha$ ultimately leading to Th1 cell-mediated immunity and pro-inflammatory responses (Shinohara et al. 2006). The same group has also suggested that iOPN expression in conventional DCs is permissive for Th17 $\mathrm{T}$ cell responses (Shinohara et al. 2008b). Th17 $\mathrm{T}$ cells are a subset of $\mathrm{T}$ helper cells producing IL-17. They are considered developmentally distinct from Th1 and Th2 cells and are thought to play a key role in autoimmune diseases including the tissue injury associated with these conditions (Steinman 2007). Thus iOPN expression may allow for autoimmune type disease progression. Indeed, OPN accelerates the progression of experimental autoimmune encephalomyelitis (EAE), a model of multiple sclerosis (Chabas et al. 2001; Hur et al. 2007; Jansson et al. 2002; Shinohara et al. 2006, $2008 \mathrm{~b})$. Others have found that iOPN may associate with the intracellular domain of CD44 and with the ezrin/ radixin/moesin (ERM) protein ezrin. iOPN in this context may modulate cytoskeletal rearrangements important for macrophage migration and osteoclast fusion (Zhu et al. 2004; Zohar et al. 2000).

A summary of the structural features of OPN is shown in Fig. 1.

\section{The role of OPN in inflammation}

OPN regulates the immune system at many different levels. It serves as a chemotactic molecule to promote the migration of inflammatory cells to the wound site and acts as an adhesive protein to retain cells at the site. OPN also functions as a proinflammatory cytokine and can modulate the immune response by enhancing expression of Th1 cytokines and matrix degrading enzymes (Weber et al. 2002; Bruemmer et al. 2003). OPN plays a pivotal role in T cell and macrophage responses during cell mediated immune responses against bacterial and viral pathogens (Ashkar et al. 2000). More recently, OPN has also been shown to modulate dendritic cell responses and neutrophil chemotaxis. 
Fig. 1 OPN structural features. The cell adhesive domains are indicated in color. The known specific integrin receptors for each adhesion domain are also shown in color. The calcium $\left(\mathrm{Ca}^{2+}\right)$ binding domains are shown in yellow and other matrix binding domains are in black. Also shown are known phosphorylation sites $(\mathrm{P})$. Arrows indicate known cleavage sites for thrombin and MMPs. Thrombin cleavage site in blue and MMPs cleavage site in green

\section{Macrophages}

OPN is not expressed in circulating monocytes, but is dramatically upregulated during macrophage differentiation and constitutes one of the major macrophage products (Krause et al. 1996). OPN is known to be induced in macrophages by several inflammatory cytokines, including TNF- $\alpha$, IL- $1 \beta$, IFN- $\gamma$, and IL-6, and other factors including angiotensin-II, oxidizedLDL, and phorbol-ester are known inducers of OPN in macrophages (Nakamachi et al. 2007; Ogawa et al. 2005; Bruemmer et al. 2003). More recently, Liver X Receptor and Peroxisome proliferatoractivated receptor $\alpha$ antagonists have been shown to suppress OPN expression (Nakamachi et al. 2007; Ogawa et al. 2005). Functionally OPN plays a key role in macrophage biology by regulating migration, survival, phagocytosis, and pro-inflammatory cytokine production (Bruemmer et al. 2003; Nyström et al. 2007).

We and others have shown that OPN serves as a potent chemoattractant for macrophages (Bruemmer et al. 2003; Persy et al. 2003; Giachelli et al. 1998; Panzer et al. 2001). Functional inhibition of OPN and genetic ablation of OPN in mice greatly impair macrophage recruitment in several models of acute inflammation. In OPN-null mice acute macrophage infiltration was greatly diminished compared to wild-type mice in an obstructed kidneys model (Ophascharoensuk et al. 1999), and in a thioglycollate induced peritonitis model (Bruemmer et al. 2003). Further, purified OPN induced macrophage accumulation when injected in rat dermis and following intradermal injection of N-formyl-met-leu-phe (FMLP), a potent macrophage chemotactic peptide. The OPN effect was neutralized by an anti-OPN blocking antibody (Giachelli et al. 1998). In a rat model of heart injury OPN was highly expressed in the granulation tissue associated macrophages, and it was downregulated with healing progression and formation of the fibrotic scar (Murry et al. 1994). Wound healing studies in mice also indicate that OPN is expressed during the acute inflammatory phase at very high levels in infiltrating leukocytes and other cell types where it appears to regulate leukocyte infiltration and activation as well as proper matrix organization (Liaw et al. 1998). Interestingly, downregulation of OPN at the wound site with antisense mRNA diminished macrophage infiltration and accelerated wound healing (Mori et al. 2008).

OPN also modifies chronic inflammatory responses. Chronic inflammation is characterized by the persistence of macrophages at sites of injury and disease. Deficits in macrophage accumulation have been noted in OPN-null mice when challenged with chronic inflammatory conditions, including atherosclerosis, delayed-type hypersensitivity (Yu et al. 1998; Ashkar et al. 2000), granulomatous disease (Weber et al. 2002; Nau et al. 1999), and biomaterial implantation (Steitz et al. 2002; Tsai et al. 2005). These data suggest that OPN may be particularly important in promoting migration and retention of macrophages at sites of acute and chronic inflammation. We have also shown that OPN regulates foreign body giant cell (FBGC) formation in vitro and in vivo. In a recent paper we described that despite the defect in macrophage recruitment, OPN-null mice formed more FBGCs on the surface of the implant. In vitro, OPN inhibited macrophage fusion to form FBGCs in a dose dependent manner (Tsai et al. 2005).

In vitro, OPN-null macrophages exhibit reduced basal migration and impaired migration towards MCP-1, despite the fact that wild type and OPN-null macrophages express comparable levels of CCR-2, the MCP-1 receptor. This may be a consequence of a lack of a permissive pro-migratory substrate, and the reduced expression of CD44 observed in OPN-null macrophages. CD44 is well known to be essential for macrophage migration (Marcondes et al. 2008), and its expression is upregulated by OPN in macrophages (Chellaiah et al. 2003). Macrophages from OPN-null mice are also more susceptible to programmed cell death (Bruemmer et al. 2003). Together with impaired migration, macrophage apoptosis may further contribute the 
impaired macrophage accumulation observed in OPN-null mice in response to acute and chronic inflammatory stimuli.

In addition to regulating macrophage migration, OPN can also modulate the cytokine production by macrophages. OPN stimulates production of IL-12 while inhibiting the production of IL-10, thereby promoting Th1 cell mediated responses (Weber et al. 2002; Ashkar et al. 2000). Interestingly, these results were mediated by different receptors. IL-12 production was mediated via an $\mathrm{N}$-terminal fragment interaction with $\alpha_{\mathrm{v}} \beta_{3}$ integrin, while IL-10 was inhibited via a C-terminal fragment, possibly via the CD44 receptor. OPN regulation of IL-12 and IL-10 were also demonstrated in vivo in an angiotensin II (AngII)-accelerated model of atherosclerosis. In this model, Bruemmer at al. showed reduced expression of IL-12 and an increased expression of IL-10 in ApoE-/OPN-/- AngII treated mice compared to ApoE-/-OPN+/+ AngII treated control mice by RT-PCR of whole mouse aortas. These results correlated with less macrophage rich lesions and lower expression of the macrophage marker CD68 (Bruemmer et al. 2003).

While OPN is generally classified as a pro-inflammatory cytokine, it also appears to have anti-inflammatory effects. OPN is a potent trans-repressor of inducible nitric oxide synthase (iNOS) expression in macrophages (Rollo et al. 1996). OPN represses inducible nitric oxide synthase (iNOS) by increasing Stat1 ubiquitination and proteasome mediated degradation of Stat1, consequently inhibiting Stat1 mediated iNOS transcription and protein expression (Gao et al. 2007). NO feedback inhibits its own synthesis by increasing transcription of OPN (Guo et al. 2001). OPN inhibition of NO may be particularly relevant for tumor cell evasion of inflammation (Wai et al. 2006; Crawford et al. 1998)

Finally, a recent study suggests that OPN may play a role in macrophage differentiation. Using siRNA to stably silence the expression of OPN in RAW 264.7 cells, Nystrom et al. showed that OPN silenced cells displayed an altered phenotype with monocyte-like characteristics (Nystrom et al. 2007). Further, OPN silenced cells had decreased expression of macrophage scavenger receptor A type 1 (Msr-1), a macrophage differentiation marker. While these studies are intriguing, the phenotype could not be rescued by the addition of exogenous OPN suggesting non-receptor mediated effects or iOPN may be involved.

Together, these data suggest that OPN may be particularly important in promoting migration and retention of macrophages at sites of acute and chronic inflammation by regulating multiple macrophage functions. These studies also emphasize the importance of macrophage-derived OPN in the regulation of OPN's functions, suggesting that macrophages are both a source and target of OPN.
Neutrophils

While much is known about the role of OPM in macrophage biology, relatively few studies have explored the function of OPN in neutrophils. Neutrophils express low levels of OPN (Koh et al. 2007). However, OPN is important for the recruitment and migration of neutrophils, as neutrophils from OPN-null mice display reduced chemotaxis toward AMLP and in vivo the recruitment of neutrophils to the peritoneal cavity in response to sodium periodate is impaired in OPN-null mice (Koh et al. 2007). OPN-null mice also have impaired neutrophil infiltration into liver when challenged with concanavalin A induced hepatitis (Diao et al. 2004). Despite these defects in migration and chemotaxis, OPN-null neutrophils do not display reduced destructive capacity in terms of phagocytosis, the generation of reactive oxygen species, or cytokine production (Koh et al. 2007). Recent reports indicate that polymeric OPN interacts with $\alpha_{9} \beta_{1}$ on neutrophils and serves as a potent neutrophil chemoattractant (Nishimichi et al. 2009).

\section{T-cells}

OPN is also known as Eta-1 (early $\mathrm{T}$ lymphocyte activation gene 1) for its high expression in activated $\mathrm{T}$ cells and it plays an important role in the induction of cell mediated immune responses through the regulation of $\mathrm{T}$ cells. Following activation, naïve CD4 $\mathrm{T}$ cells can differentiate towards Th1, Th2, or Th17 cells which differ in effector function. The development of Th1 cells leads to cellmediated immunity while development of Th2 cells provides humoral immunity. Th17 cells are associated with autoimmunity. OPN is not expressed in naïve T-cells but it is strongly upregulated in response to $\mathrm{T}$ cell receptor ligation (Shinohara et al. 2005). OPN functions in T cells by mediating migration, adhesion, and co-stimulating $\mathrm{T}$ cell proliferation (O’Regan et al. 1999; Patarca et al. 1993). Shinohara et al. have shown that OPN gene expression in $\mathrm{T}$ cells is controlled by T-bet, a transcription factor that promotes CD4+ T helper cell lineage commitment to Th1 (Shinohara et al. 2005). Further, T-bet-dependent expression of OPN in T cells is essential for efficient skewing of CD4 T and CD8 T cells toward the Th1 and type 1 CD8 T cell (Tc1) pathway, respectively (Shinohara et al. 2005). In vivo, OPN-null mice display impaired Th1 responses to the intracellular bacterium Listeria monocytogenes and the viral pathogen HSV1 (herpes simplex virus type 1) both of which depend on the induction of IL-12 for protection (Ashkar et al. 2000). Indeed, mice deficient in OPN have decreased IL-12 and IFN- $\gamma$ production, while IL-10 levels are enhanced (Bruemmer et al. 2003). Further studies have shown that OPN regulates CD3-mediated T cell expression 
of IFN- $\gamma$ and CD40L (O'Regan et al. 2000), which in turn stimulates IL-12 production from leukocytes. Together these findings suggest that OPN may play a role in polarizing early Th1 responses. More recently, OPN has also been shown to regulate IFN- $\gamma$ and IL-17 production by T cells in an $\alpha_{\mathrm{v}} \beta_{3}$-dependent manner and to dampen IL-10 in a CD44-dependent manner (Murugaiyan et al. 2008). This appears to be important for the progression of experimental autoimmune encephalomyelitis (EAE), a murine model of multiple sclerosis. The same authors found that during EAE, OPN expression was elevated in DCs both in the periphery and in the CNS (Murugaiyan et al. 2008). This correlated with the increased expression of OPN in DCs and increased expression of OPN receptors CD44 and $\alpha_{\mathrm{v}} \beta_{3}$ on T cells isolated from patients affected by multiple sclerosis (Murugaiyan et al. 2008). These results may indicate that OPN produced by DCs in EAE is linked to the production of IL-17 (Murugaiyan et al. 2008; Shinohara et al. 2008b). Recent studies indicate that OPN enhances the survival of autoreactive T cells in a NF- $\mathrm{kB}$ dependent manner. Enhanced OPN-induced T cell survival also appears to promote progression of EAE (Hur et al. 2007). In addition, an anti-OPN antibody has been shown to promote apoptosis of activated T cells, particularly CD4+ $\mathrm{T}$ cells, by inhibiting activation of NF-KB and by altering the balance between the proapoptotic proteins, Bim and Bax, and the antiapoptotic protein, Bcl-2, in a model of rheumatoid arthritis (Fan et al. 2008).

Finally, a subset of lymphocytes bridging innate and adaptive immunity called invariant natural killer T (iNKT) cells has also been shown to be regulated by OPN. Diao et al. found that the number of peripheral iNKT cells was significantly reduced in OPN-deficient mice compared with wild-type mice. This appeared to be consequence of impairment of intrathymic iNKT cell maturation and significant alteration of iNKT cell function as well (Diao et al. 2004).

\section{Dendritic cells}

OPN plays a key role in DC maturation, migration, and polarization. Interestingly, immature IL-4 and GM-CSF differentiated DCs express high levels of OPN, and OPN production decreases when DCs are stimulated with LPS and CD40L (Kawamura et al. 2005; Schulz et al. 2008). These findings suggest differential regulation of OPN in DCs and macrophages. During macrophage differentiation, OPN expression increases as monocytes adhere and differentiate into macrophages (Krause et al. 1996).

In vitro OPN stimulates $\mathrm{DC}$ migration in a dose dependent manner in both the presence and absence of divalent cations, and studies with blocking antibodies have indicated a role for the OPN receptors $\alpha_{v} \beta_{3}$ and CD44 in
OPN induced DC migration (Weiss et al. 2001). In vivo, DCs in OPN-null mice display a defect in DC trafficking to the lymph nodes resulting in reduced contact hypersensitivity responses (Weiss et al. 2001). Despite the influence of OPN on DC migratory capacity, treatment with recombinant OPN does not affect the expression of CCR5 and CCR7, chemokine receptors which are involved in DC migration (Schulz et al. 2008). Recently, it has also been suggested that OPN modulates different subset of DCs in the airway hypersensitivity reaction (a model of asthma). It appears that OPN increased the reaction during primary sensitization but decreased the reaction in the challenge phase, perhaps by mediating differential recruitment of different DCs (plamacytoid and conventional) subsets to the lymph nodes (Xanthou et al. 2007).

OPN also influences DC cytokine production. In coculture systems, OPN induces DC secretion of TNF- $\alpha$ and IL-12p70 which stimulates secretion of IFN- $\gamma$ by T-cells (Renkl et al. 2005). By augmenting DC production of IL12, OPN can enhance Th1 polarization.

As mentioned earlier, recent studies illustrate the critical role of intracellular OPN in IFN- $\alpha$ production by plasmacytoid DCs, a specialized subset of DCs which produce high levels of type I interferons upon stimulation (Shinohara et al. 2006). IFN- $\alpha$ produced by pDCs activates NK cells, and consequently OPN deficient mice display impaired IFN- $\alpha$ dependent natural killer cell responses. Further, iOPN appears to decrease IL-27 in conventional DCs, leading to increases in Th17 responses (Shinohara et al. 2008b).

\section{Other biological functions of OPN}

\section{Wound healing}

OPN is a key cytokine regulating tissue repair. OPN is present at sites of wound healing where it serves as a chemotactic molecule to recruit inflammatory cells to the site of injury. Wound healing studies in OPN-null mice have elucidated the role of OPN in tissue repair. Compared to wild type mice, incisional wounds made in OPN-null mice displayed alterations in the matrix architecture especially collagen fiber diameter, and had more residual debris (Liaw et al. 1998). Furthermore, macrophages at the wound site in OPN-null mice expressed higher levels of mannose receptor, suggesting OPN may contribute to macrophage polarization and thus regulate healing responses. Mannose receptor expression in macrophages is associated with reduced pro-inflammatory (IL-1, IL-6, IL-12, and TNF- $\alpha$ ) cytokine secretion, upregulation of pro-healing molecules (IL-10 and TGF- $\beta$ ), and certain phagocytic receptors (Sica et al. 2008). 
A more recent study by Mori et al. explored the use of local OPN knockdown at the site of wound healing by delivering antisense oligodeoxynucleotides from a drug delivery polymer gel. Consistent with the finding in OPNnull mice, in OPN knockdown wounds the diameter of collagen fibrils was also smaller than in control wounds. Further, OPN knockdown hindered the migration of inflammatory cells to the wound site and resulted in accelerated healing and a reduction in granulation tissue formation and scarring (Mori et al. 2008). Whether the infiltrated macrophages in OPN knockdown wounds also had a less pro-inflammatory and more pro-healing phenotype was not established, however, this may be behind the observed accelerated healing. The reduced size of the collagen fibers that was observed in the OPN-null and OPN knockdown wounds may be related to the finding that OPN has been shown to bind directly to collagen type I (Chen et al. 1992), and to interact with collagen types II, III, IV, and V (Bulter et al. 1995). Further, it has recently been shown that OPN is necessary for TGF- $\beta 1$-induced myofibroblast differentiation and OPN-null fibroblasts exhibited less spreading, less resistance to detachment, and a reduction in collagen gel contraction (Lenga et al. 2008). These studies indicate a role for OPN in promoting proper collagen organization and regulating ECM and myofibroblast interactions.

\section{Vascular disease}

To date, several studies have investigated the role of OPN in the progression of atherosclerosis. In hyperlipidemic apoEdeficient mice, Matsui et al, showed that osteopontin deficiency significantly reduces atherosclerotic lesion size in female ApoE-/-OPN-/- mice compared to ApoE-/-OPN+/+ mice after 36 weeks on a normal chow diet (Matsui et al. 2003). Similarly, studies in ApoE/LDLreceptor/OPN triple knockout mice showed that OPN deficiency resulted in decreased atherosclerotic lesion size and an increase in the number of apoptotic cells in lesions (Strom et al. 2004). Bone marrow transplantation studies in an angiotensin IIaccelerated model of atherosclerosis indicated that leukocyte derived OPN contributes to OPN mediated development of atherosclerosis (Bruemmer et al. 2003). These studies suggest that OPN promotes macrophage accumulation and retention in the atherosclerotic lesions, thus contributing to the chronicity of the disease.

OPN also modulates other vascular cells associated with vascular disease. In human atherosclerotic lesions, OPN is expressed in smooth muscle cells (SMC), angiogenic endothelial cells, and macrophages and it is re-expressed in SMCs associated with human restenotic lesions (Giachelli et al. 1993; Panda et al. 1997). Consistently, animal models have confirmed the role of OPN in promoting SMC migration and proliferation (Liaw et al. 1994; Isoda et al. 2002). All these data indicate that during injury, OPN enhances the proliferation, migration, and accumulation of smooth muscle and endothelial cells involved in repair and remodeling processes of the vasculature.

\section{Cancer}

OPN is highly expressed in transformed cells and is found in a variety of cancers (Wai and Kuo 2008). OPN overexpression can confer metastatic phenotype to nonmetastatic, benign transformed cells, and increased OPN expression correlates with tumor progression, poor prognosis and increased invasiveness. In metastatic models, OPN has been shown to induce matrix proteases MMP2 and uPA in an integrin-dependent manner (Mi et al. 2006). Further, OPN has been shown to bind and activate MMP3. Thus, the ability of OPN to stimulate migration and matrix breakdown could contribute to invasiveness and to the metastatic potential of tumors cells. OPN may also promote tumorigenesis and metastasis by inhibiting apoptosis of tumor cells (Zhao et al. 2008), and by stimulating neovascularization (Wai and Kuo 2004). Finally, OPN is widely expressed by macrophages, which infiltrate tumor tissue (Brown et al. 1994; Chambers et al. 1996). Macrophage-derived OPN functions as a chemoattractant and was associated with reduced tumor burden while tumor-derived OPN appeared to inhibit macrophage function and enhance tumor growth (Crawford et al. 1998). It is possible that tumor cell-derived OPN may enhance cancer cell survival by downregulating iNOS expression and NO production in macrophages. OPN is currently being studied as a potential biomarker for cancer and there is interest in targeting OPN as a therapeutic treatment for cancer.

\section{Biomineralization}

OPN is one of the most abundant non-collagenous proteins in bone. Because of its abundance in bone, OPN has been studied as a regulator of biomineralization. OPN is a potent inhibitor of mineralization, prevents ectopic calcification, and is an inducible inhibitor of vascular calcification (Steitz et al. 2002). OPN binds hydroxyapatite and calcium ions thereby physically inhibiting crystal formation and growth in vivo. Studies in OPN-null mice have shown that OPN-/bones are hypermineralized, with increased mineral content and crystal size (Boskey et al. 2002). OPN also plays a role in osteoclast differentiation and osteoblast recruitment and function (Rittling et al. 1998). OPN functions in osteoclast migration to sites of resorption and is crucial for normal resorption and bone turnover (Chellaiah et al. 2003).

OPN appears also to be an important regulator of vascular calcification and is associated with mineralized deposits in 
humans (Giachelli et al. 1993). In mice, OPN levels are greatly elevated in the spontaneously mineralizing arteries of $\mathrm{MGP}^{-/-}$mice and we have recently shown that OPN is major inducible inhibitor of arterial medial calcification in this system (Steitz et al. 2002). Vascular calcification is now recognized as a marker of atherosclerotic plaque burden as well as a major contributor to loss of arterial compliance and increased pulse pressure seen with age, diabetes, and renal insufficiency. These findings suggest that OPN may be an important inhibitor of arterial mineral deposition under conditions of injury and disease, and that strategies to replenish OPN might be useful to prevent or treat ectopic calcification, including vascular calcification.

\section{Conclusions}

OPN is emerging as a key regulator of immune cell biology. Most of the evidence indicates that OPN is transiently expressed in leukocytes during acute inflammation. However, persistence of OPN expression by immune cells exacerbates chronic inflammatory diseases. Clinically, this is manifested by increased OPN plasma levels in Crohn's disease (Agnholt et al. 2007), cancer (El-Tanani et al. 2006), atherosclerosis, and autoimmune diseases including lupus (Kariuki et al. 2009), multiple sclerosis (Comabella et al. 2005), and rheumatoid arthritis (Sennels et al. 2008).

Mechanistically, OPN appears to regulate innate immune cells (macrophages and DCs) and adaptive immune cells (T cells) at multiple levels (see Fig. 2). Recent data point to a role for OPN in the regulation of cross-talk between DCs and $\mathrm{T}$ cells and their subsequent polarization in Th1 and more recently in Th17 cells.

In vitro and in vivo studies show that both the thrombin and MMP proteolytically cleaved OPN fragments possess higher activity than the full-length form. In addition, at least the thrombin cleaved fragment also gains a new cell interacting domain (SVVYGLR). Antibodies specifically reacting toward the SVVYGLR (human and primate) or the SLAYGLR (murine) sequences have been shown effective in ameliorating rheumatoid arthritis symptoms in nonhuman primates and mice (Yamamoto et al. 2003, 2007).

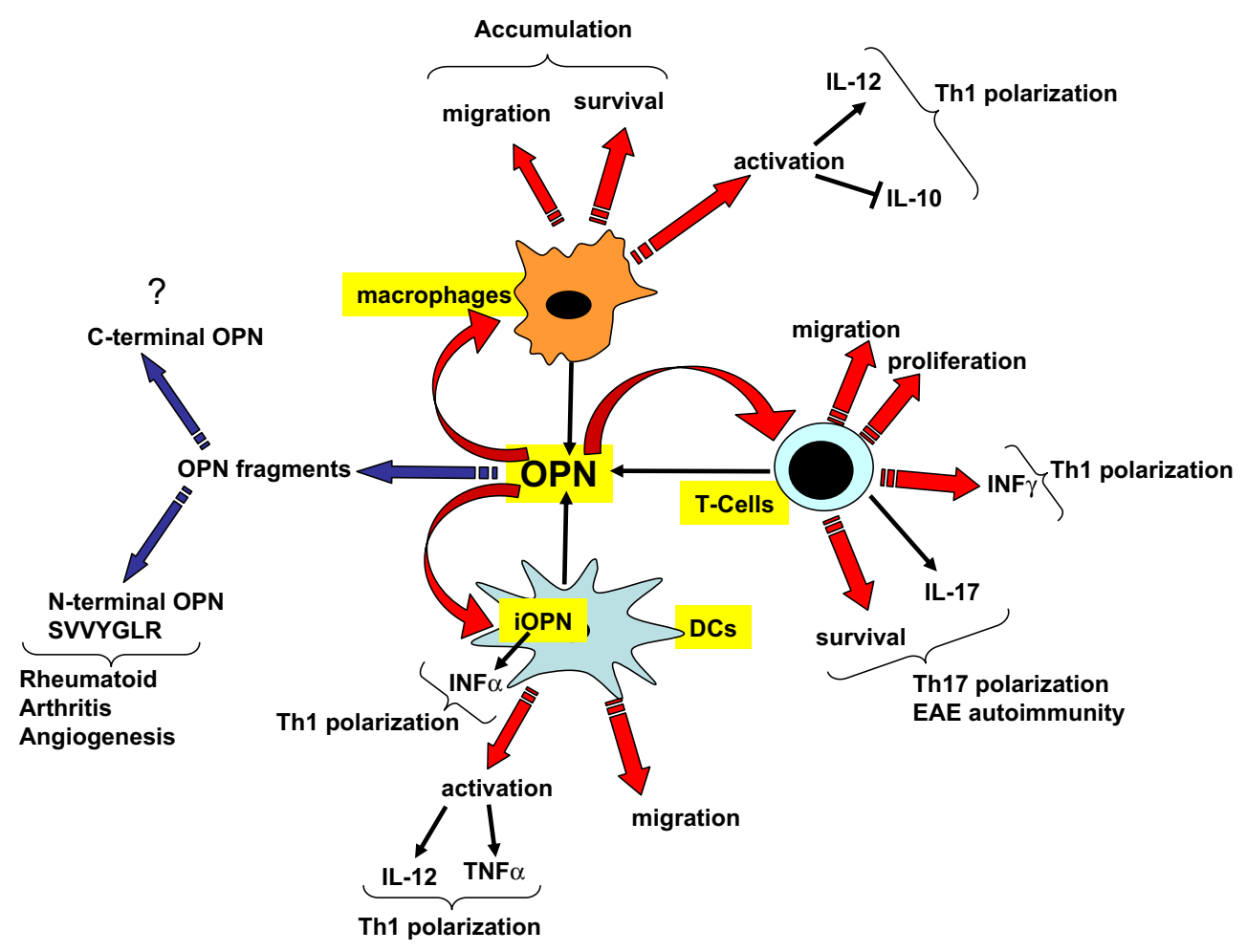

Fig. 2 OPN regulation of immune and inflammatory cells. OPN is secreted and modulates the function of macrophages, DCs and T Cells. OPN may induce macrophage accumulation by promoting migration and survival. Further, OPN induces IL-12 and inhibits IL-10 in macrophages, thus, propagating a Th1 response. In DCs OPN appears to modulate their function as an extracellular soluble cytokine and also as an intracellular molecule (iOPN). Both OPN forms appear to induce Th1 polarization. Extracellular OPN appears to induce expression of IL-12 and TNF- $\alpha$, and iOPN appears to regulate the production of INF- $\alpha$. In T cells OPN induces migration, proliferation, survival, and IL-17 secretion. These two latter functions have been correlated with Th17 responses and autoimmunity. Further, OPN appears to induce IFN- $\gamma$ secretion by $\mathrm{T}$ cells thus propagating a Th1 response. Finally, the N-terminal OPN fragment (containing the activated adhesive domain SVVYGLR) may be important in the propagation of rheumatoid arthritis 
Therefore, during inflammation, it is likely that the secreted, less potent, full-length OPN is rapidly cleaved and thus activated. Understanding differences in the mechanisms and structure/function relationships governing the proinflammatory properties of OPN could help create specific therapeutics aimed at targeting chronic inflammatory diseases selectively.

Acknowledgements Dr. Giachelli's laboratory is funded by NIH grants HL62329, HL081785, and HL18645, and grant \#2361524 from the Washington State Life Science Discovery Fund.

Open Access This article is distributed under the terms of the Creative Commons Attribution Noncommercial License which permits any noncommercial use, distribution, and reproduction in any medium, provided the original author(s) and source are credited.

\section{References}

Agnholt J, Kelsen J, Schack L, Hvas CL, Dahlerup JF, Sorensen ES (2007) Osteopontin, a protein with cytokine-like properties, is associated with inflammation in Crohn's disease. Scand J Immunol 65(5):453-460

Agnihotri R, Crawford HC, Haro H, Matrisian LM, Havrda MC, Liaw L (2001) Osteopontin, a novel substrate for matrix metalloproteinase-3 (stromelysin-1) and matrix metalloproteinase-7 (matrilysin). J Biol Chem 276(30):28261-28267

Ashkar S, Weber GF, Panoutsakopoulou V, Sanchirico ME, Jansson M, Zawaideh S, Rittling SR, Denhardt DT, Glimcher MJ, Cantor H (2000) Eta-1 (osteopontin): an early component of type-1 (cellmediated) immunity. Science 287(5454):860-864

Bayless KJ, Davis GE (2001) Identification of dual alpha4 beta1 integrin binding sites within a 38 amino acid domain in the $\mathrm{N}$ terminal thrombin fragment of human osteopontin. J Biol Chem 276(16):13483-13489

Bellahcene A, Castronovo V, Ogbureke KU, Fisher LW, Fedarko NS (2008) Small integrin-binding ligand N-linked glycoproteins (SIBLINGs): multifunctional proteins in cancer. Nat Rev Cancer $8(3): 212-226$

Beninati S, Senger DR, Cordella-Miele E, Mukherjee AB, Chackalaparampil I, Shanmugam V, Singh K, Mukherjee BB (1994) Osteopontin: its transglutaminase-catalyzed posttranslational modifications and cross-linking to fibronectin. $\mathrm{J}$ Biochem 115(4):675-682

Boskey AL, Spevak L, Paschalis E, Doty SB, McKee MD (2002) Osteopontin deficiency increases mineral content and mineral crystallinity in mouse bone. Calcif Tissue Int 71 (2):145-154

Brown LF, Berse B, Van de Water L, Papadopoulos-Sergiou A, Perruzzi CA, Manseau EJ, Dvorak HF, Senger DR (1992) Expression and distribution of osteopontin in human tissues: widespread association with luminal epithelial surfaces. Mol Biol Cell 3(10):1169-1180

Brown LF, Papadopoulos-Sergiou A, Berse B, Manseau EJ, Tognazzi K, Perruzzi CA, Dvorak HF, Senger DR (1994) Osteopontin expression and distribution in human carcinomas. Am J Pathol 145(3):610-23

Bruemmer D, Collins AR, Noh G, Wang W, Territo M, AriasMagallona S, Fishbein MC, Blaschke F, Kintscher U, Graf K, Law RE, Hsueh WA (2003) Angiotensin II-accelerated atherosclerosis and aneurysm formation is attenuated in osteopontindeficient mice. J Clin Invest 112(9):1318-1331
Bulter W (1995) Structural and functional domains of osteopontin. Ann NY Acad Sci 760:6-11

Chabas D, Baranzini SE, Mitchell D, Bernard CC, Rittling SR, Denhardt DT, Sobel RA, Lock C, Karpuj M, Pedotti R, Heller R, Oksenberg JR, Steinman L (2001) The influence of the proinflammatory cytokine, osteopontin, on autoimmune demyelinating disease. Science 294(5547):1731-1735

Chambers AF, Wilson SM, Kerkvliet N, O'Malley FP, Harris JF, Casson AG (1996) Osteopontin expression in lung cancer. Lung Cancer 15(3):311-23

Chellaiah MA, Kizer N, Biswas R, Alvarez U, Strauss-Schoenberger J, Rifas L, Rittling SR, Denhardt DT, Hruska KA (2003) Osteopontin deficiency produces osteoclast dysfunction due to reduced CD44 surface expression. Mol Biol Cell 14(1):173-189

Chen Y, Bal BS, Gorski JP (1992) Calcium and collagen binding properties of osteopontin, bone sialoprotein, and bone acidic glycoprotein-75 from bone. J Biol Chem 267(34):24871-24878

Chen J, Singh K, Mukherjee BB, Sodek J (1993) Developmental expression of osteopontin (OPN) mRNA in rat tissues: evidence for a role for OPN in bone formation and resorption. Matrix 13 (2): $113-123$

Christensen B, Nielsen MS, Haselmann KF, Petersen TE, Sorensen ES (2005) Post-translationally modified residues of native human osteopontin are located in clusters: identification of 36 phosphorylation and five O-glycosylation sites and their biological implications. Biochem J 390(Pt 1):285-292

Comabella M, Pericot I, Goertsches R, Nos C, Castillo M, Blas Navarro J, Rio J, Montalban X (2005) Plasma osteopontin levels in multiple sclerosis. J Neuroimmunol 158(1-2):231-239

Crawford HC, Matrisian LM, Liaw L (1998) Distinct roles of osteopontin in host defense activity and tumor survival during squamous cell carcinoma progression in vivo. Cancer Res 58 (22):5206-5215

Dean RA, Overall CM (2007) Proteomics discovery of metalloproteinase substrates in the cellular context by iTRAQ labeling reveals a diverse MMP-2 substrate degradome. Mol Cell Proteomics 6(4):611-623

Denda S, Reichardt L, Muller U (1998) Identification of osteopontin as a novel ligand for the integrin alpha 8 betal and potential role for this integrin-ligand interaction in kidney morphogenesis. Molecular biology of the cell 9(6):1425-1435

Diao H, Kon S, Iwabuchi K, Kimura C, Morimoto J, Ito D, Segawa T, Maeda M, Hamuro J, Nakayama T, Taniguchi M, Yagita H, Van Kaer L, Onoe K, Denhardt D, Rittling S, Uede T (2004) Osteopontin as a mediator of NKT cell function in $\mathrm{T}$ cellmediated liver diseases. Immunity 21(4):539-550

El-Tanani MK, Campbell FC, Kurisetty V, Jin D, McCann M, Rudland PS (2006) The regulation and role of osteopontin in malignant transformation and cancer. Cytokine Growth Factor Rev 17(6):463-474

Fan K, Dai J, Wang H, Wei H, Cao Z, Hou S, Qian W, Li B, Zhao J, $\mathrm{Xu} \mathrm{H}$, Yang C, Guo Y (2008) Treatment of collagen-induced arthritis with an anti-osteopontin monoclonal antibody through promotion of apoptosis of both murine and human activated $\mathrm{T}$ cells. Arthritis Rheum 58(7):2041-2052

Fisher LW, Torchia DA, Fohr B, Young MF, Fedarko NS (2001) Flexible structures of SIBLING proteins, bone sialoprotein, and osteopontin. Biochem Biophys Res Commun 280(2):460-465

Gao YA, Agnihotri R, Vary CP, Liaw L (2004) Expression and characterization of recombinant osteopontin peptides representing matrix metalloproteinase proteolytic fragments. Matrix Biol 23(7):457-466

Gao C, Guo H, Mi Z, Grusby MJ, Kuo PC (2007) Osteopontin induces ubiquitin-dependent degradation of STAT1 in RAW264.7 murine macrophages. J Immunol 178(3):1870-1881

Giachelli CM, Bae N, Almeida M, Denhardt DT, Alpers CE, Schwartz SM (1993) Osteopontin is elevated during neointima formation in 
rat arteries and is a novel component of human atherosclerotic plaques. J Clin Invest 92(4):1686-1696

Giachelli CM, Lombardi D, Johnson RJ, Murry CE, Almeida M (1998) Evidence for a role of osteopontin in macrophage infiltration in response to pathological stimuli in vivo. Am J Pathol 152(2):353-358

Golledge J, Muller J, Shephard N, Clancy P, Smallwood L, Moran C, Dear AE, Palmer LJ, Norman PE (2007) Association between osteopontin and human abdominal aortic aneurysm. Arterioscler Thromb Vasc Biol 27(3):655-660

Green PM, Ludbrook SB, Miller DD, Horgan CM, Barry ST (2001) Structural elements of the osteopontin SVVYGLR motif important for the interaction with alpha(4) integrins. FEBS Lett 503(1):75-79

Guo H, Cai CQ, Schroeder RA, Kuo PC (2001) Osteopontin is a negative feedback regulator of nitric oxide synthesis in murine macrophages. J Immunol 166(2):1079-1086

Hamada Y, Nokihara K, Okazaki M, Fujitani W, Matsumoto T, Matsuo M, Umakoshi Y, Takahashi J, Matsuura N (2003) Angiogenic activity of osteopontin-derived peptide SVVYGLR. Biochem Biophys Res Commun 310(1):153-157

Hamada Y, Egusa H, Kaneda Y, Hirata I, Kawaguchi N, Hirao T, Matsumoto T, Yao M, Daito K, Suzuki M, Yatani H, Daito M, Okazaki M, Matsuura N (2007) Synthetic osteopontin-derived peptide SVVYGLR can induce neovascularization in artificial bone marrow scaffold biomaterials. Dent Mater J 26(4):487-492

Hu DD, Lin EC, Kovach NL, Hoyer JR, Smith JW (1995) A biochemical characterization of the binding of osteopontin to integrins alpha $\mathrm{v}$ beta 1 and alpha v beta 5. J Biol Chem 270(44):26232-26238

Hur EM, Youssef S, Haws ME, Zhang SY, Sobel RA, Steinman L (2007) Osteopontin-induced relapse and progression of autoimmune brain disease through enhanced survival of activated $\mathrm{T}$ cells. Nat Immunol 8(1):74-83

Isoda K, Nishikawa K, Kamezawa Y, Yoshida M, Kusuhara M, Moroi M, Tada N, Ohsuzu F (2002) Osteopontin plays an important role in the development of medial thickening and neointimal formation. Circ Res 91(1):77-82

Ito K, Kon S, Nakayama Y, Kurotaki D, Saito Y, Kanayama M, Kimura C, Diao H, Morimoto J, Matsui Y, Uede T (2009) The differential amino acid requirement within osteopontin in alpha4 and alpha9 integrin-mediated cell binding and migration. Matrix Biol 28(1):11-19

Jansson M, Panoutsakopoulou V, Baker J, Klein L, Cantor H (2002) Cutting edge: attenuated experimental autoimmune encephalomyelitis in eta-1/osteopontin-deficient mice. J Immunol 168(5):2096-9

Jono S, Peinado C, Giachelli CM (2000) Phosphorylation of osteopontin is required for inhibition of vascular smooth muscle cell calcification. J Biol Chem 275(26):20197-20203

Kariuki SN, Moore JG, Kirou KA, Crow MK, Utset TO, Niewold TB (2009) Age- and gender-specific modulation of serum osteopontin and interferon-alpha by osteopontin genotype in systemic lupus erythematosus. Genes Immun 10:487-494

Katagiri YU, Sleeman J, Fujii H, Herrlich P, Hotta H, Tanaka K, Chikuma S, Yagita H, Okumura K, Murakami M, Saiki I, Chambers AF, Uede $\mathrm{T}$ (1999) CD44 variants but not CD44s cooperate with beta1containing integrins to permit cells to bind to osteopontin independently of arginine-glycine-aspartic acid, thereby stimulating cell motility and chemotaxis. Cancer Res 59(1):219-226

Kawamura K, Iyonaga K, Ichiyasu H, Nagano J, Suga M, Sasaki Y (2005) Differentiation, maturation, and survival of dendritic cells by osteopontin regulation. Clin Diagn Lab Immunol 12(1):206-212

Kazanecki CC, Uzwiak DJ, Denhardt DT (2007) Control of osteopontin signaling and function by post-translational phosphorylation and protein folding. J Cell Biochem 102(4):912-924

Koh A, da Silva AP, Bansal AK, Bansal M, Sun C, Lee H, Glogauer M, Sodek J, Zohar R (2007) Role of osteopontin in neutrophil function. Immunology 122(4):466-475
Kon S, Ikesue M, Kimura C, Aoki M, Nakayama Y, Saito Y, Kurotaki D, Diao H, Matsui Y, Segawa T, Maeda M, Kojima T, Uede T (2008) Syndecan-4 protects against osteopontin-mediated acute hepatic injury by masking functional domains of osteopontin. J Exp Med 205(1):25-33

Krause SW, Rehli M, Kreutz M, Schwarzfischer PJD, Andreesen R (1996) Differential screening identifies genetic markers of monocyte to macrophage maturation. J Leukoc Biol 60(4):540-5

Lenga Y, Koh A, Perera AS, McCulloch CA, Sodek J, Zohar R (2008) Osteopontin expression is required for myofibroblast differentiation. Circ Res 102(3):319-327

Liaw L, Almeida M, Hart CE, Schwartz SM, Giachelli CM (1994) Osteopontin promotes vascular cell adhesion and spreading and is chemotactic for smooth muscle cells in vitro. Circ Res 74 (2):214-224

Liaw L, Skinner MP, Raines EW, Ross R, Cheresh DA, Schwartz SM, Giachelli CM (1995) The adhesive and migratory effects of osteopontin are mediated via distinct cell surface integrins. Role of alpha v beta 3 in smooth muscle cell migration to osteopontin in vitro. J Clin Invest 95(2):713-724

Liaw L, Birk DE, Ballas CB, Whitsitt JS, Davidson JM, Hogan BL (1998) Altered wound healing in mice lacking a functional osteopontin gene (spp 1). J Clin Invest 101(7):1468-1478

Maeda K, Takahashi K, Takahashi F, Tamura N, Maeda M, Kon S, Uede T, Fukuchi Y (2001) Distinct roles of osteopontin fragments in the development of the pulmonary involvement in sarcoidosis. Lung 179(5):279-291

Marcondes MC, Poling M, Watry DD, Hall D, Fox HS (2008) In vivo osteopontin-induced macrophage accumulation is dependent on CD44 expression. Cell Immunol 254(1):56-62

Marroquin CE, Downey L, Guo H, Kuo PC (2004) Osteopontin increases CD44 expression and cell adhesion in RAW 264.7 murine leukemia cells. Immunol Lett 95(1):109-112

Martin SM, Schwartz JL, Giachelli CM, Ratner BD (2004) Enhancing the biological activity of immobilized osteopontin using a type-1 collagen affinity coating. J Biomed Mater Res A 70(1):10-19

Matsui Y, Rittling SR, Okamoto H, Inobe M, Jia N, Shimizu T, Akino M, Sugawara T, Morimoto J, Kimura C, Kon S, Denhardt D, Kitabatake A, Uede T (2003) Osteopontin deficiency attenuates atherosclerosis in female apolipoprotein E-deficient mice. Arterioscler Thromb Vasc Biol 23(6):1029-1034

Mi Z, Guo H, Wai PY, Gao C, Kuo PC (2006) Integrin-linked kinase regulates osteopontin-dependent MMP-2 and uPA expression to convey metastatic function in murine mammary epithelial cancer cells. Carcinogenesis 27(6):1134-1145

Mori R, Shaw T, Martin P (2008) Molecular mechanisms linking wound inflammation and fibrosis: knockdown of osteopontin leads to rapid repair and reduced scarring. J Exp Med 205(1):43-51

Mukherjee BB, Nemir M, Beninati S, Cordella-Miele E, Singh K, Chackalaparampil I, Shanmugam V, DeVouge MW, Mukherjee AB (1995) Interaction of osteopontin with fibronectin and other extracellular matrix molecules. Ann N Y Acad Sci 760:201-212

Murry CE, Giachelli CM, Schwartz SM, Vracko R (1994) Macrophages express osteopontin during repair of myocardial necrosis. Am J Pathol 145(6):1450-1462

Murugaiyan G, Mittal A, Weiner HL (2008) Increased osteopontin expression in dendritic cells amplifies IL-17 production by CD4+ $\mathrm{T}$ cells in experimental autoimmune encephalomyelitis and in multiple sclerosis. J Immunol 181(11):7480-7488

Nagata T, Todescan R, Goldberg HA, Zhang Q, Sodek J (1989) Sulphation of secreted phosphoprotein I (SPPI, osteopontin) is associated with mineralized tissue formation. Biochem Biophys Res Commun 165(1):234-240

Nakamachi T, Nomiyama T, Gizard F, Heywood EB, Jones KL, Zhao Y, Fuentes L, Takebayashi K, Aso Y, Staels B, Inukai T, Bruemmer D (2007) PPARalpha agonists suppress osteopontin 
expression in macrophages and decrease plasma levels in patients with type 2 diabetes. Diabetes 56(6):1662-1670

Nau GJ, Liaw L, Chupp GL, Berman JS, Hogan BL, Young RA (1999) Attenuated host resistance against Mycobacterium bovis BCG infection in mice lacking osteopontin. Infect Immun 67 (8):4223-4230

Nishimichi N, Higashikawa F, Kinoh HH, Tateishi Y, Matsuda H, Yokosaki Y (2009) Polymeric osteopontin employs integrin alpha 9beta 1 as a receptor and attracts neutrophils by presenting a de novo binding site. J Biol Chem 284:14769-14776

Nystrom T, Duner P, Hultgardh-Nilsson A (2007) A constitutive endogenous osteopontin production is important for macrophage function and differentiation. Exp Cell Res 313(6):1149-1160

O'Brien ER, Garvin MR, Stewart DK, Hinohara T, Simpson JB, Schwartz SM, Giachelli CM (1994) Osteopontin is synthesized by macrophage, smooth muscle, and endothelial cells in primary and restenotic human coronary atherosclerotic plaques. Arterioscler Thromb 14(10):1648-1656

Ogawa D, Stone JF, Takata Y, Blaschke F, Chu VH, Towler DA, Law RE, Hsueh WA, Bruemmer D (2005) Liver x receptor agonists inhibit cytokine-induced osteopontin expression in macrophages through interference with activator protein-1 signaling pathways. Circ Res 96(7):e59-67

Ohri R, Tung E, Rajachar R, Giachelli CM (2005) Mitigation of ectopic calcification in osteopontin-deficient mice by exogenous osteopontin. Calcif Tissue Int 76(4):307-315

Ohshima S, Yamaguchi N, Nishioka K, Mima T, Ishii T, UmeshitaSasai M, Kobayashi H, Shimizu M, Katada Y, Wakitani S, Murata N, Nomura S, Matsuno H, Katayama R, Kon S, Inobe M, Uede T, Kawase I, Saeki Y (2002) Enhanced local production of osteopontin in rheumatoid joints. J Rheumatol 29(10):2061-2067

Ophascharoensuk V, Giachelli CM, Gordon K, Hughes J, Pichler R, Brown P, Liaw L, Schmidt R, Shankland SJ, Alpers CE, Couser WG, Johnson RJ (1999) Obstructive uropathy in the mouse: role of osteopontin in interstitial fibrosis and apoptosis. Kidney Int 56 (2):571-580

O'Regan AW, Chupp GL, Lowry JA, Goetschkes M, Mulligan N, Berman JS (1999) Osteopontin is associated with $\mathrm{T}$ cells in sarcoid granulomas and has $\mathrm{T}$ cell adhesive and cytokine-like properties in vitro. J Immunol 162(2):1024-1031

O'Regan AW, Hayden JM, Berman JS (2000) Osteopontin augments CD3-mediated interferon-gamma and CD40 ligand expression by $\mathrm{T}$ cells, which results in IL-12 production from peripheral blood mononuclear cells. J Leukoc Biol 68(4):495-502

Panda D, Kundu GC, Lee BI, Peri A, Fohl D, Chackalaparampil I, Mukherjee BB, Li XD, Mukherjee DC, Seides S, Rosenberg J, Stark K, Mukherjee AB (1997) Potential roles of osteopontin and alphaVbeta3 integrin in the development of coronary artery restenosis after angioplasty. Proc Natl Acad Sci U S A 94 (17):9308-9313

Panzer U, Thaiss F, Zahner G, Barth P, Reszka M, Reinking R, Wolf G, Helmchen U, Stahl R (2001) Monocyte chemoattractant protein-1 and osteopontin differentially regulate monocytes recruitment in experimental glomerulonephritis. Kidney Int 59 (5): 1762-1769

Patarca R, Freeman GJ, Singh RP, Wei FY, Durfee T, Blattner F, Regnier DC, Kozak CA, Mock BA, Morse HC 3rd, Jerrells TR, Cantor H (1989) Structural and functional studies of the early T lymphocyte activation 1 (Eta-1) gene. Definition of a novel T cell-dependent response associated with genetic resistance to bacterial infection. J Exp Med 170(1):145-161

Patarca R, Saavedra R, Cantor H (1993) Molecular and cellular basis of genetic resistance to bacterial infection: the role of the early Tlymphocyte activation-1/osteopontin gene. Crit Rev Immunol 13 (3-4):225-246
Persy V, Verhulst A, Ysebaert D, De Greef K, De Broe M (2003) Reduced postischemic macrophage infiltration and interstitial fibrosis in osteopontin knockout mice. Kidney Int 63(2):543-553

Renkl AC, Wussler J, Ahrens T, Thoma K, Kon S, Uede T, Martin SF, Simon JC, Weiss JM (2005) Osteopontin functionally activates dendritic cells and induces their differentiation toward a Th1polarizing phenotype. Blood 106(3):946-955

Rittling SR, Matsumoto HN, McKee MD, Nanci A, An XR, Novick KE, Kowalski AJ, Noda M, Denhardt DT (1998) Mice lacking osteopontin show normal development and bone structure but display altered osteoclast formation in vitro. J Bone Miner Res 13(7):1101-1111

Rollo EE, Laskin DL, Denhardt DT (1996) Osteopontin inhibits nitric oxide production and cytotoxicity by activated RAW264.7 macrophages. J Leukoc Biol 60(3):397-404

Schulz G, Renkl AC, Seier A, Liaw L, Weiss JM (2008) Regulated osteopontin expression by dendritic cells decisively affects their migratory capacity. J Invest Dermatol 128(10):2541-2544

Senger DR, Perruzzi CA, Papadopoulos-Sergiou A, Van de Water L (1994) Adhesive properties of osteopontin: regulation by a naturally occurring thrombin-cleavage in close proximity to the GRGDS cell-binding domain. Mol Biol Cell 5(5):565-574

Senger DR, Perruzzi CA (1996) Cell migration promoted by a potent GRGDS-containing thrombin-cleavage fragment of osteopontin. Biochim Biophys Acta 1314(1-2):13-24

Senger DR, Perruzzi CA, Papadopoulos A (1989) Elevated expression of secreted phosphoprotein I (osteopontin, 2ar) as a consequence of neoplastic transformation. Anticancer Res 9(5):1291-1299

Sennels H, Sorensen S, Ostergaard M, Knudsen L, Hansen M, Skjodt H, Peters N, Colic A, Grau K, Jacobsen S (2008) Circulating levels of osteopontin, osteoprotegerin, total soluble receptor activator of nuclear factor-kappa B ligand, and high-sensitivity C-reactive protein in patients with active rheumatoid arthritis randomized to etanercept alone or in combination with methotrexate. Scand J Rheumatol 37(4):241-247

Shinohara ML, Jansson M, Hwang ES, Werneck MB, Glimcher LH, Cantor H (2005) T-bet-dependent expression of osteopontin contributes to $\mathrm{T}$ cell polarization. Proc Natl Acad Sci U S A 102(47):17101-17106

Shinohara ML, Lu L, Bu J, Werneck MB, Kobayashi KS, Glimcher LH, Cantor H (2006) Osteopontin expression is essential for interferon-alpha production by plasmacytoid dendritic cells. Nat Immunol 7(5):498-506

Shinohara ML, Kim HJ, Kim JH, Garcia VA, Cantor H (2008a) Alternative translation of osteopontin generates intracellular and secreted isoforms that mediate distinct biological activities in dendritic cells. Proc Natl Acad Sci U S A 105(20):72357239

Shinohara ML, Kim JH, Garcia VA, Cantor H (2008b) Engagement of the type I interferon receptor on dendritic cells inhibits $\mathrm{T}$ helper 17 cell development: role of intracellular osteopontin. Immunity 29(1):68-78

Sica A, Larghi P, Mancino A, Rubino L, Porta C, Totaro MG, Rimoldi M, Biswas SK, Allavena P, Mantovani A (2008) Macrophage polarization in tumour progression. Semin Cancer Biol 18(5):349-55

Singh K, DeVouge MW, Mukherjee BB (1990) Physiological properties and differential glycosylation of phosphorylated and nonphosphorylated forms of osteopontin secreted by normal rat kidney cells. J Biol Chem 265(30):18696-18701

Smith LL, Giachelli CM (1998) Structural requirements for alpha 9 beta 1-mediated adhesion and migration to thrombin-cleaved osteopontin. Exp Cell Res 242(1):351-360

Smith LL, Cheung HK, Ling LE, Chen J, Sheppard D, Pytela R, Giachelli CM (1996) Osteopontin N-terminal domain contains a cryptic adhesive sequence recognized by alpha9beta1 integrin. J Biol Chem 271(45):28485-28491 
Smith LL, Greenfield BW, Aruffo A, Giachelli CM (1999) CD44 is not an adhesive receptor for osteopontin. J Cell Biochem 73 (1):20-30

Sorensen ES, Hojrup P, Petersen TE (1995) Posttranslational modifications of bovine osteopontin: identification of twentyeight phosphorylation and three O-glycosylation sites. Protein Sci 4(10):2040-2049

Steinman L (2007) A brief history of $\mathrm{T}(\mathrm{H}) 17$, the first major revision in the $\mathrm{T}(\mathrm{H}) 1 / \mathrm{T}(\mathrm{H}) 2$ hypothesis of $\mathrm{T}$ cell-mediated tissue damage. Nat Med 13(2):139-45

Steitz SA, Speer MY, McKee MD, Liaw L, Almeida M, Yang H, Giachelli CM (2002) Osteopontin inhibits mineral deposition and promotes regression of ectopic calcification. Am J Pathol 161 (6):2035-2046

Strom A, Franzen A, Wangnerud C, Knutsson AK, Heinegard D, Hultgardh-Nilsson A (2004) Altered vascular remodeling in osteopontin-deficient atherosclerotic mice. J Vasc Res 41(4):314-322

Takafuji V, Forgues M, Unsworth E, Goldsmith P, Wang XW (2007) An osteopontin fragment is essential for tumor cell invasion in hepatocellular carcinoma. Oncogene 26(44):6361-6371

Takahashi K, Takahashi F, Tanabe KK, Takahashi H, Fukuchi Y (1998) The carboxyl-terminal fragment of osteopontin suppresses arginine-glycine-asparatic acid-dependent cell adhesion. Biochem Mol Biol Int 46(6):1081-1092

Tsai AT, Rice J, Scatena M, Liaw L, Ratner BD, Giachelli CM (2005) The role of osteopontin in foreign body giant cell formation. Biomaterials 26(29):5835-5843

Wai PY, Kuo PC (2004) The role of osteopontin in tumor metastasis. J Surg Res 121(2):228-241

Wai PY, Kuo PC (2008) Osteopontin: regulation in tumor metastasis. Cancer Metastasis Rev 27(1):103-118

Wai PY, Guo L, Gao C, Mi Z, Guo H, Kuo PC (2006) Osteopontin inhibits macrophage nitric oxide synthesis to enhance tumor proliferation. Surgery 140(2):132-140

Weber GF, Ashkar S, Glimcher MJ, Cantor H (1996) Receptor-ligand interaction between CD44 and osteopontin (Eta-1). Science 271 (5248):509-512

Weber GF, Zawaideh S, Hikita S, Kumar VA, Cantor H, Ashkar S (2002) Phosphorylation-dependent interaction of osteopontin with its receptors regulates macrophage migration and activation. J Leukoc Biol 72(4):752-761

Weiss JM, Renkl AC, Maier CS, Kimmig M, Liaw L, Ahrens T, Kon S, Maeda M, Hotta H, Uede T, Simon JC (2001) Osteopontin is involved in the initiation of cutaneous contact hypersensitivity by inducing Langerhans and dendritic cell migration to lymph nodes. J Exp Med 194(9):1219-1229
Wesson JA, Johnson RJ, Mazzali M, Beshensky AM, Stietz S, Giachelli C, Liaw L, Alpers CE, Couser WG, Kleinman JG, Hughes J (2003) Osteopontin is a critical inhibitor of calcium oxalate crystal formation and retention in renal tubules. J Am Soc Nephrol 14(1):139-147

Xanthou G, Alissafi T, Semitekolou M, Simoes DC, Economidou E, Gaga M, Lambrecht BN, Lloyd CM, Panoutsakopoulou V (2007) Osteopontin has a crucial role in allergic airway disease through regulation of dendritic cell subsets. Nat Med 13(5):570-578

Xuan J, Hota C, Chambers A (1994) Recombinant GST-human osteopontin fusion protein i...[J Cell Biochem. 1994]—PubMed Result. J Cell Biochem 54(2):247-255

Yamamoto N, Sakai F, Kon S, Morimoto J, Kimura C, Yamazaki H, Okazaki I, Seki N, Fujii T, Uede T (2003) Essential role of the cryptic epitope SLAYGLR within osteopontin in a murine model of rheumatoid arthritis. J Clin Invest 112(2):181-188

Yamamoto N, Nakashima T, Torikai M, Naruse T, Morimoto J, Kon S, Sakai F, Uede T (2007) Successful treatment of collagen-induced arthritis in non-human primates by chimeric anti-osteopontin antibody. Int Immunopharmacol 7(11):1460-1470

Yokosaki Y, Matsuura N, Sasaki T, Murakami I, Schneider H, Higashiyama S, Saitoh Y, Yamakido M, Taooka Y, Sheppard D (1999) The integrin alpha(9)beta(1) binds to a novel recognition sequence (SVVYGLR) in the thrombin-cleaved amino-terminal fragment of osteopontin. J Biol Chem 274(51):36328-36334

Yokosaki Y, Tanaka K, Higashikawa F, Yamashita K, Eboshida A (2005) Distinct structural requirements for binding of the integrins alphavbeta6, alphavbeta3, alphavbeta5, alpha5beta1 and alpha9beta1 to osteopontin. Matrix Biol 24(6):418-427

Yu XQ, Nikolic-Paterson DJ, Mu W, Giachelli CM, Atkins RC, Johnson RJ, Lan HY (1998) A functional role for osteopontin in experimental crescentic glomerulonephritis in the rat. Proc Assoc Am Physicians 110(1):50-64

Zhao J, Dong L, Lu B, Wu G, Xu D, Chen J, Li K, Tong X, Dai J, Yao S, Wu M, Guo Y (2008) Down-regulation of osteopontin suppresses growth and metastasis of hepatocellular carcinoma via induction of apoptosis. Gastroenterology 135(3):956-968

Zhu B, Suzuki K, Goldberg HA, Rittling SR, Denhardt DT, McCulloch CA, Sodek J (2004) Osteopontin modulates CD44dependent chemotaxis of peritoneal macrophages through Gprotein-coupled receptors: evidence of a role for an intracellular form of osteopontin. J Cell Physiol 198(1):155-167

Zohar R, Suzuki N, Suzuki K, Arora P, Glogauer M, McCulloch CA, Sodek J (2000) Intracellular osteopontin is an integral component of the CD44-ERM complex involved in cell migration. J Cell Physiol 184(1):118-130 